same error was discovered in time to avert a fatal termination, and now we have to add a fresh instance. Mr. Squire, indeed, asserted at the Pharmaceutical Society that people who did not properly examine the label of their medicine bottle deserved to be poisoned. Putting aside this rash dictum, which probably not even its author would be disposed to defend, we deduce from the recurrence of these lamentable accidents amongst persons of intelligence, of capacity, and of station, accustomed to adopt all ordinary precautions, but nevertheless too often guilty of fatal inadvertence in this matter, a striking proof of the necessity for the adoption of such an additional safeguard against accident as has been suggested in the employment of contracted necks for what are called safety medicine bottles. Had the liniment so swallowed in either of these cases been furnished to the patient in a quadrangular fluted bottle with contracted neck, properly labeled, these errors could not have occurred-these lives must have been saved. The logic of facts so stern, in some aspects so awful, cannot long be resisted. This mechanical precaution, or an equivalent one, must necessarily be adopted spontaneously by all conscientious vendors of medicine; its neglect cannot be regarded with indifference by the public, or passed over by the Legislature.

\section{PROHIBITED FOOD.}

IT is gratifying to see the proofs of the useful influence of recent prosecutions for the introduction of diseased animal food into London. More than two tons of meat unfit for human food were seized last week in the markets. In every case the salesmen gave notice to the inspectors that the meat had been sent for sale. Prosecutions instituted during the week for exposing for sale the carcases of diseased and rotten sheep have in two instances been successful, and the salesmen have been fined. Very soon we shall cease to hear of such prosecutions, for the salesmen, when careless of higher motives, will dread the shame and exposure attendant on conviction; and they will not neglect voluntarily to inform the inspectors when such meat is consigned to them for sale. This, however, still stops short of what should be done. There are greater offenders than the salesmen of diseased meat, and these are the consigners. With them the offence is wilful, and with some of them habitual. The ends of justice will not be fully accomplished unless the names and addresses of the consigners are furnished in every instance, and means are found to punish their offence and thus prevent its recurrence. Finally, it is needful that the arrangements for destroying the diseased meat, when seized, be perfected; for there is still great reason to fear that some part of it finds its way back, in some form or other, into the markets, and is consumed as human food.

\section{HOMCOPATHY IN THE GUERNSEY MILITIA.}

THF redoubtable chief of the Government at Guernsey, although not to be moved by the representations of bis medical staff or the clamours of the press, has yielded a tardy and undignified concession to the remonstrances which he derided. He had gone far towards the disorganization of the Medical Department of the Militia over which he presided. He had driven to resignation the staff and regimental surgeons of his Militia, and had seen himself under the necessity of accepting those of the three senior and most respected officers of the Service, Drs. Hoskins, De Lisle, and Mansell, "by desire of the Home-Secretary;" while he compelled the remaining medical officers to do duty "under protest." He had found it necessary to suppress altogether, by a general order of the 15th Feb., the medical staff, reduced as it was to the sole personnel of Dr. Ozanne. After so many sacrifices, General Slade finds that he has laboured, blustered, and endured in vain. By the Iast general order, Dr. Ozanne is removed from his equiwocal position by being "attached to head-quarters," so that his name will be erased from the muster-roll of the Militia. Thus General Slade bas beaten a retreat, but it is unskilfully covered. The lasting offence and the permanent slight shown to the Medical Service in sacrificing their chiefs and disregarding their earnest remonstrances, until the unity and efficiency of the whole Medical Department were dangerously compromised, are but ill-repaired by a proceeding which only partially removes the cause of offence, and in no way redresses the wrong which has already been done.

\section{THE APPOINTMENT OF PHYSICIAN TO THE QUEEN.}

IT is a matter of national concern, that the attendant upon the Queen should not be attached to a Fever Hospital. The risk, however small, of carrying infection into the household of the Sovereign, ought on no account to be incurred. It cannot be doubted that Dr. Jenner will resign his appointment at the Fever Hospital.

\section{Corespondence.}

"Audi alteram partem."

\section{MODERN IITHOTRITY :}

\section{DR. CIVIALE'S CLINICAL EXPERIENCE. To the Editor of THe Lancet.}

SIR, - I have just received a letter from my friend and former instructor, Dr. Civiale, of Paris, in which he requests me to translate and send to you for publication the result of his practice in operating for stone in the bladder during the past year (1 560$)$. Dr. Civiale's reputation as the inventor and perfector of modern lithotrity is so well known, that I lose no time in sending you this interesting document.

It may be in the memory of some of your readers that at the Medical Society of London, and in THE LANCET of Jan. 21st, $1 \delta 60$, I called attention to the following proposition, as one which appeared to me to be of the very highest importance:That stone in the bladder may, by the exercise of fair intelligence and skill, be deprived of nearly all its severity and danger to life; since it may, in the great majority of cases, be detected in its early stage and when of small size; and because i ts destruction in that stage may be accomplished with safety and certainty by lithotrity.

I cannot forbear appealing to the following letter as a remarkable illustration of that great and pregnant truth.

The facts of this letcer suggest several subjects for critical remark to the English surgeon, which I shall not touch upon here. Taken altogether, I think that English experience amongst those who practise lithotrity, will not much suffer by comparison with the excellent results of the great master's work.

The following is a literal translation of the article which Dr. Civiale has just published in the Gazette des Sciences, \&c., and which he has sent me for the purpose named.

I am, Sir, your obedient servant,

Wimpole-stret, Feb. 23rd, 1861. HENRY Trompson, F.R.C.S.

RECORD OF CIVIALE'S CLINICAL FXPERIENCE IN THE TREATMENT OF STONE DURING THE YRAR 1860.

I treated, in 1560,54 patients affected with stone in the bladder: 36 in my private practice, and 15 in the hospital.

A. Private patients. - Twenty-six of these patients had stone for the first time; 10 had been already operated on by other surgeons or by myself; the stone having re-appeared, fresh operations were necessary.

I operated on 26 of these patients by lithotrity: 24 are cured; in 2 others I was obliged to relinquish the operation, which appeared to aggravate the morbid condition of the bladder. One of these patients has died; the other still lives, and the stone remains in the bladder.

All those calculous patients who were most farourably circumstanced, whose organs were still sound and in good health, and who had no other disease than a small stone, obtained a rapid and easy cure. For this class of patients the application 
of lithotrity appears to me to have reached great perfection: in fact, the stone is destroyed in a few minutes, and its débris are expelled with the urine; all suffering ceases, and the health is re-establisbed and maintained. Surely this is all one can desire in the treatment of calculus.

But lithotrity gives such good results only when its application is restricted to favourable cases, in which the stone has not had time to grow large, and to produce in the bladder lesions capable of altering the form and natural conditions of that organ. I hasten to add, however, that the proportion of favourable cases augments every day, and that they will become more and more numerous in proportion as calculous pa. tients, informed as to their condition by their medical attendants, submit themselves to operation at the outset of the malady.

Ten of those I treated had not displayed this prudence; they only sought the aid of art when their existence had become insupportable on account of in cessant pain.

In two of them the diseased condition of the urinary organs offered an obstacle to the application of lithotrity, and as lithotomy was equally contra-indicated, death occurred from the progress of the eomplaint.

Four, having large stones, were operated on by lithotomy: one adult obtained a rapid and complete cure, the wound having cicatrized by the tenth day; in another adult the convalescence was tedious, and the cure incomplete. Two old men died in the second week after the operation.

Two patients are still under treatment: one will be operated on by lithotrity, the other by lithotomy.

In two others, who became ill at Paris when the winter set in and returned home, the treatment has been postponed until the spring.

B. Hospital patients. - Amongst the 18 calculous patients admitted under my care, there were 3 women and 15 men, all adults, some old people.

The first of these women, who had suffered during a Jong period of time, was so bad that any operation was contra-indicated; and the patient returned to her family.

The second was in favourable condition as regards her general health, but the calculus was engaged in the urethra, where it was maintained by violent contraction of the bladder. A division of the canal sufficed to accomplish the extraction This proceeding appeared to me, in these circumstances, to be preferable to that of crushing, which would have been very tedious and painful. The patient was rapidly cured.

The third woman, an account of whom I have published, presented one of those extraordinary cases which one meet with at distant intervals. The stone, a phosphatic one, was formed upon a mass of teeth, of litile bones, and of hair, arising from a hair-cyst which had opened in to the bladder. All these bodies and the stone itself were successfully extracted by lithotrity.

Four of the male patients were not in the condition which the application of lithotrity demands. Two were cut; one was cured, but the other has still a fistula. The third refused to submit to the knife, which indeed offered small cbance of success : he died of renal disease. The fourth is under treatment.

Another male patient was the subject, at the same time, of a stone of middle size and of strangulated hernia, requiring immediate operation, from which he died.

The 10 remaining patients submitted to lithotrity were freed from the stone, but the cure in all was not complete. Amongst them, 2 retained some pain and disturbance in the functions of the bladder, arising from organic lesions of that viscus, and against which lithotrity avails no more than lithotomy.

The recent cases observed at the Hospital Necker present a fact worthy of notice.

Calculous patients form two great classes. In one, which embraces two-thirds of the cases, the organs retain their natural condition. Indeed it is only oceasionally, and espe. cially after bodily exercise, that the stone provokes some functional disorders, which cease by repose. Here the stone forming of itself the whole malady, it suffices to destroy or extract it by surgical operation for the patient to obtain a complete and speedy cure.

In the other class, the phosphate of lime, or the ammoniacomagnesian phosphatic calculi form and are developed under the influence of a morbid condition of the urinary apparatus. It is not uncommon for this state to persist after operation, to deprive the patient of the complete benefit of treatment, and even to favour the development of a new stoue. These cases predominate in the foregoing account.

To resume. Of 54 calculous patients, of which I have just presented a table, 37 bave been treated by lithotrity. In 2 cases I was obliged to relinquish the treatment; 1 died; another retains his stone; 2 of them have not obtained a complete cure, because the stone has not formed the sole malady, but they are greatly relieved. The rest are cured.

7 were submitted to lithotomy, which saved 4 of them; but in 2 of these the cure is incomplete.

10 have not been submitted to any operation; 3 have died from the progress of the malady, and 1 after the operation for hernia; 1 continues to live with his stone. 3 are under treatment, and will be submitted, 1 to lithotrity, and 2 to lithotomy. In 2 cases the operations are postponed.

These facts prove anew the danger of long retaining the stone, and the utility of lithotrity when we apply it at an early period of the complaint.

\section{THE TURKISH BATH. To the Elitor of THE LANCET.}

SrR,-I always hail with gratification the appearance of any remedy which promises to be an efficient addition to the too limited means which we possess of alleviating the many "ills which flesh is heir to." At the same time, it appears to me to be the duty of every medienl practitioner to scrutinize and investigate to the extent of his ability and opportunities the various remedial agents that are every now and then brought before the public, in order that he, as one of the guardians of the public health, may protect the community from the baneful influence of too great credulity, and at the same time preserve to his profession the reputation of disinterestedness and progression.

Prominently before the public and the profession at the present time is the question of the efficacy of the Turkish bath in the treatment of various forms of disease. Now here is a remedy which is open to anyone to prove; a remedy about which there can be no secrecy, and the eficacy of which can and ought to be proved or clisproved by direct experiments.

If this remedy be allowed to $r_{0}$ to swell the stock-in-trade of quacks and arlventurers, it will be the fault of the members of our own profession, who it must be confessed are very loth to seek for any remedy beyond the limits of their own sur. geries.

My attention was called some years ago to the use of the Turkish bath in this country, and from the first I feit a strong impression that, judiciously and cantionsly applied, it would prove a valuable aid in the treatment of many forms of disease. I was then practising at Rickmansworth, in Kertfordshire, when a gentleman distinguished alike for his original genius and his ecentricilies took up his abole in $\mathrm{my}$ immediate neighbourhood. I allade to Mr. David Urquhart. On further acquaintance I soon discoverel that he was an enthusiast in his views of the use of the Turkish bath, as indeed he was about everything oriental. He lost no time, and spared no expense, in fixing up a Tnrkish bath at his own residence, and freely admitted anyone to use it who felt so disposed. Mr. Urquhart and his family daily used the bath; and not only this, they adopted also the Eastern style of elothing, and even the youngest members of his family, then infants, passed through a severe winter clad in only one garment, and that a thin tunic. From Mr. Urquhart I learnt a great leal of the use and effects of the Turkish bath; and of one thing I soon became convinced-that exposure to great and sudden variations of temperature, under certain circumstances, had nothing of that injurious influence which popular opinion attributed to it. I must also confess that Mr. Urquhart failed to convince me that in the Turkish bath he had discovered the remedy for all human ailments. From what I saw then, and from what I have since learnt of the application of this bath, I am convinced that it is a valuable remedy, but requiring careful limitation; and that it will prove exceedingly injurious if used indiscriminately and without professional guidance.

With your permission I will proceed to indicate a few points towards which I think our investigations should be especially directed, in order to discover the proper use and the influence of this remedial agent.

In the first place, have we sufficiently considered the different effect this bath is likely to exert over the Turk and the Englishman, having especial reference to their respective temperaments, habits of life, and the climate in which they live? Can the active, fox-hunting, cricketing, boating Englishman bear the same kind of treatment that benefits and gratifies the indolent, languid, luxurious Turk? Or may not even our own countrymen, when in the East, and subject to the same influ. 